\title{
A Sensitive and Rapid Method for Detecting Formaldehyde in Brain Tissues
}

\author{
Xiangpei Yue, ${ }^{1}$ Yaoyue Zhang, ${ }^{2}$ Wen Xing, ${ }^{2}$ Yutong Chen, ${ }^{2}$ Chenyang $\mathrm{Mu}^{2} \mathrm{Zhan} \mathrm{Miao,}^{2}$ \\ Peichun Ge, ${ }^{2}$ Tingting $\mathrm{Li}^{2}{ }^{2}$ Rongqiao He, ${ }^{1,3}$ and Zhiqian Tong ${ }^{1}$ \\ ${ }^{1}$ Alzheimer's Disease Center, Beijing Institute for Brain Disorders, Capital Medical University, Beijing 100069, China \\ ${ }^{2}$ Beijing No. 12 Laboratory of Brain and Cognitive Sciences, Beijing 100071, China \\ ${ }^{3}$ State Key Laboratory of Brain and Cognitive Sciences, Institute of Biophysics, Beijing 100101, China
}

Correspondence should be addressed to Tingting Li; momohuiyi@163.com, Rongqiao He; herq@sun5.ibp.ac.cn, and Zhiqian Tong; tzqbeida@163.com

Received 26 April 2017; Accepted 5 July 2017; Published 24 September 2017

Academic Editor: Nady Braidy

Copyright (C) 2017 Xiangpei Yue et al. This is an open access article distributed under the Creative Commons Attribution License, which permits unrestricted use, distribution, and reproduction in any medium, provided the original work is properly cited.

The existing methods for detecting formaldehyde (FA) in brain samples are expensive and require sophisticated experimental procedures. Here, we established a highly sensitive and selective spectrophotometric method, which is based on a reaction in which FA reacts with colorless reagent 4-amino-3-penten-2-one (Fluoral-P) to produce a yellow compound, 3,5-diacetyl-1,4dihydrolutidine (DDL), which can be detected by a spectrophotometer at $420 \mathrm{~nm}$ at room temperature. The sensitive response time point was found to be at the first hour, and the optimal $\mathrm{pH}$ of derivative reaction was $\mathrm{pH}$ 6.0. The limit of detection (LOD) and the limits of quantization (LOQ) for detecting FA were $0.5 \mu \mathrm{M}$ and $2.5 \mu \mathrm{M}$, respectively. Using this method, an abnormally high level of FA was detected in both the brains of FA-injected mice and autopsy hippocampus tissues from patients with Alzheimer's disease. This finding suggests that the modified Fluoral-P method is effective for measuring levels of FA in the brains.

\section{Introduction}

Formaldehyde (FA) is an industrial chemical product that is widely used to manufacture building materials and household products and is released from several sources within indoor environments, such as particle board, household products, and plywood [1]; hence, a large number of workers and inhabitants are inevitably exposed to FA [2]. Initial studies showed that gaseous FA could cause carcinogenic and fetal abnormalities [3], and clinical and epidemiological investigations have found that work-related exposure to FA results in headaches, anxiety, fatigue, sleep disorders, in particular, cognitive disorders $[4,5]$. In addition, the results of animal experiments have consistently revealed that gaseous FA exposure induced abnormal behaviors, including spatial memory deficits [6-8].

Interestingly, abnormal levels of endogenous FA have been detected in humans exposed to exogenous FA [9], as well as in aged mice and rats [10], in healthy older adults with cognitive disorders [11], and in patients suffering from Alzheimer's disease (AD) [12]. Documentary evidence indicates that a direct intracerebroventricular injection of excess FA into animal models causes central nervous system damage and, in particular, a marked impairment in memory [13-16]. These data strongly support the notion that excess FA in the hippocampus leads to cognitive deficits.

In view of the neurotoxic effects of $\mathrm{FA}$, various analytical methods have been developed to detect FA in animal tissues. The earliest determination method for measuring FA in brain tissues $(\sim 0.16-0.24 \mathrm{mM})$ was carried out using gas chromatography/mass spectrometry (GC-MS) [17]. Another sensitive method, developed for the detection of FA in the liver, utilized high-performance liquid chromatography with an ultra violet detector (HPLC-UV) $[18,19]$. More recently, using a high-performance liquid chromatography with a fluorescence detector (HPLC-Fluo), we found that there was $0.25-0.32 \mathrm{mM}$ FA in the hippocampi of normal adult mice and rats [20]. Although these existing approaches 
provide some accurate and ultrasensitive assays for FA detection in the brains, several disadvantages, such as expense, sophisticated experimental procedures, and noxious analytical reagents, have limited their practical applications. Therefore, a simple, sensitive, and efficient method for determining trace amounts of FA in biological samples is needed.

Herein, we report that a highly sensitive and selective spectrophotometric method for detecting FA in the brains of mice at room temperature has been established using a colorless reagent- 4-amino-3-penten-2-one (Fluoral-P) which selectively reacts with FA to produce a colored compound, 3,5-diacetyl-1,4-dihydrolutidine (DDL). Thus, this modified Fluoral-P method is suitable to detect brain FA and assess FA neurotoxicity.

\section{Materials and Methods}

2.1. Reagents and Chemical FA Solution. 37\% (w/v; Sigma-Aldrich, Saint Louis, USA); 4-amino-3-penten-2-one (Fluoral-P, CAS: 1118-66-7. http:/TCIchemicals.com, Japan); hydrochloric acid ( $\mathrm{HCl}, 1 \mathrm{~N}$, Sigma-Aldrich, Saint Louis, USA); sodium hydroxide $(\mathrm{NaOH}, 2 \mathrm{~N}$, SigmaAldrich); dimethyl sulfoxide (DMSO, Sigma-Aldrich, Saint Louis, USA); trichloroacetic acid (TCA, Sigma-Aldrich, Saint Louis, USA); deionized water (Milli-Q water); phosphatebuffered saline (PBS, $1 \mathrm{mM}$, Beijing Institute of Chemical Technology, China); and normal saline (NS, Beijing Institute of Chemical Technology, China) were used in the study.

2.2. Apparatuses. Refrigerator (Haier Group, Beijing, China); $\mathrm{pH}$ meter (PHS-3C, Shanghai instrument electric science instrument Limited by Share Ltd., Shanghai, China); adjustable high-speed homogenizer (FSH-2A, Liangyou Experiment Instrument Factory, Changzhou, China); Model ZD2011584 from Millipore (Nepean, Ontario, Canada); SP-Max 2300A multiskan spectrum microplate spectrophotometer (Flash spectrum of Shanghai Biological Technology Co. Ltd., Shanghai, China); and Morris water maze (Shanghai Biowill Co. Ltd., Shanghai, China) were used in the study.

2.3. Preparation of Chemical Solutions. FA stock solution (100 mM, $12.3 \mathrm{~mL})$ : FA solution $(0.1 \mathrm{~mL}, 37 \%)$ was pipetted into $12.2 \mathrm{~mL}$ of PBS ( $1 \mathrm{mM}, \mathrm{pH}$ at $4.0,5.0,6.0$, and 7.0, resp.). FA working solutions were $0.001,0.01,0.1,1$, and $10 \mathrm{mM}, \mathrm{pH}$ at 4.0, 5.0, 6.0, and 7.0, respectively. Fluoral-P store solution (500 mM): $0.05 \mathrm{~g}$ was dissolved in $1 \mathrm{~mL}$ DMSO and stored in an ice-box at $4^{\circ} \mathrm{C}$ for not more than 2 months. Fluoral-P working solutions were $0.5,5$, and $50 \mathrm{mM}, \mathrm{pH}$ at $4.0,5.0$, 6.0 , and 7.0, respectively. Trichloroacetic acid $(10 \%, w / v)$ was made in PBS (1 mM, pH 6.0) and kept in the dark.

2.4. Brain Tissue Homogenates and Extraction. Following the Morris water maze test, all mice were anesthetized with pentobarbital sodium $(10 \mathrm{mg} / \mathrm{kg}$, intraperitoneally (i.p.)) and then sacrificed by cervical dislocation. Brain tissues were immediately removed with medical scissors, rinsed in icecold PBS, and then homogenized in $0.1 \mathrm{mM}$ PBS ( $\mathrm{pH} 6.0$ ) at a ratio of $1: 4$ between brain weight and PBS volume. The brain homogenates were added into 10\% TCA solution at a volume ratio of $1: 2$. Finally, the mixtures were centrifuged at $12,000 \times \mathrm{g}$ for $10 \mathrm{~min}$ at $4^{\circ} \mathrm{C}$ and supernatants were frozen at $-80^{\circ} \mathrm{C}$ until further use.

\subsection{Protocol of Brain FA Analysis}

2.5.1. Optimal pH and Time of Derivative Reaction. To determine the optimal $\mathrm{pH}$ value of derivative reaction between Fluoral-P and FA at room temperature, five $0.1 \mathrm{~mL}$ aliquots of different concentrations of FA standard solutions (0.001, $0.01,0.1,1$, and $10 \mathrm{mM}, \mathrm{pH}$ at $4.0,5.0,6.0$, and 7.0, resp.) were added to five vials in order to prepare a series of calibration standards. In addition, $0.8 \mathrm{~mL}$ of PBS ( $\mathrm{pH}$ at 4.0, 5.0, 6.0, and 7.0 , resp.) was pipetted into a separate vial after which aliquots of $0.1 \mathrm{~mL} 5 \mathrm{mM}$ Fluoral-P solution ( $\mathrm{pH}$ at $4.0,5.0$, 6.0 , and 7.0, resp.) were added to each of the five vials. These mixtures were pipetted into 96-well plates and incubated at room temperature for $0,15,30,60,120$, and $180 \mathrm{~min}$, respectively, and the intensity of the colored derivative, DDL, was quantified by a spectrophotometer at $420 \mathrm{~nm}$.

The calibration curves which covered a FA concentration range of $0.001-1 \mathrm{mM}$ were prepared. For routine analysis, a one-point calibration in duplicate was prepared daily and used for quantitative calculation of brain samples.

2.5.2. Variations of Within-Day and Day-to-Day. Control brain samples $(n=9)$ were analyzed for DDL intensity on day 1 to evaluate the variation in within-day FA concentrations at $0,15,30,60,90,120$, and $180 \mathrm{~min}$, respectively. Another group was assayed to evaluate the variation in dayto-day FA concentrations, on day 1, 7, and 14, respectively.

2.6. Animals. All specified pathogen-free adult male C57BL/6 mice ( $n=36,6$ weeks old, 18-20 g) were provided by Capital Medical University Laboratory Animal Resources (Beijing, China) and housed in standard conditions (12 h light-dark cycle, $70 \%-80 \%$ humidity, $25 \pm 1{ }^{\circ} \mathrm{C}$ ), and food and water were provided ad libitum. All animal experiments were conducted in accordance with the National Institutes of Health Guide for the Care and Use of Laboratory Animals and were approved by the Office of Scientific Research Management of Capital Medical University, Beijing, China (AEEI-2015-032).

2.7. FA Metabolism after FA Injection and Morris Water Maze Test. Eighteen mice were used to observe FA metabolism in the brains of normal adult mice that were administered an intraperitoneal injection of either FA (i.p., $0.6 \mathrm{mM}$, $0.5 \mathrm{~mL})$ or normal saline $(0.5 \mathrm{~mL})$ at $30 \mathrm{~min}$. In addition, 18 mice were used for Morris water maze test. Nine mice were injected with FA $(0.6 \mathrm{mM}, 0.5 \mathrm{~mL}$; i.p.) for 7 consecutive days, 30 min prior to each consecutive maze evaluation. Control mice $(n=9)$ were i.p. injected with normal saline $(0.5 \mathrm{~mL})$ and underwent the same experimental procedures as above. All spatial trainings and memory retrieval experiments involving the Morris water maze were conducted as previously described $[12,13]$.

2.8. Autopsy Sample of Human. Autopsy hippocampus tissues from healthy age-matched controls with $\mathrm{ApoE}^{\varepsilon 3 / \varepsilon 3}$, and $\mathrm{AD}$ patients with $\mathrm{ApoE^{ \varepsilon 4/ \varepsilon 4 }}$ genotypes were provided by the Netherlands Brain Bank (NBB) (Supplementary Table 1 


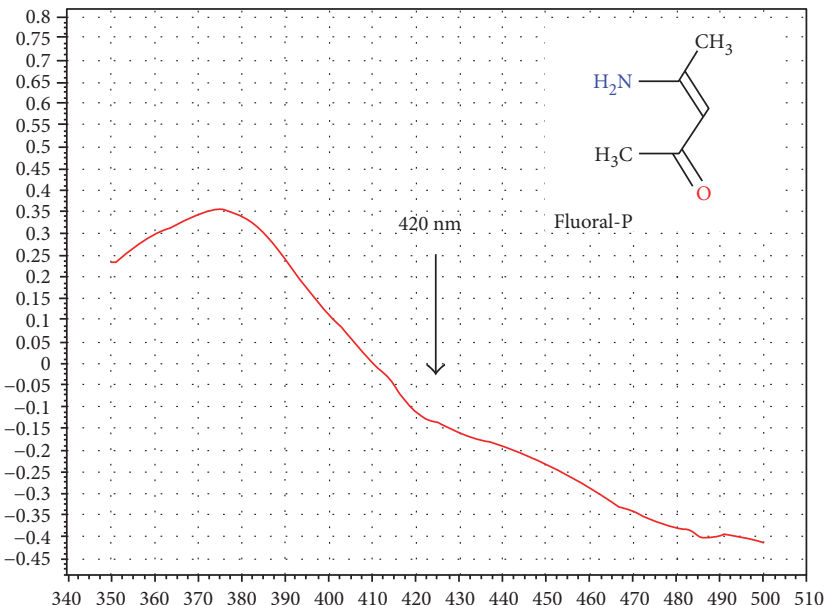

(a)

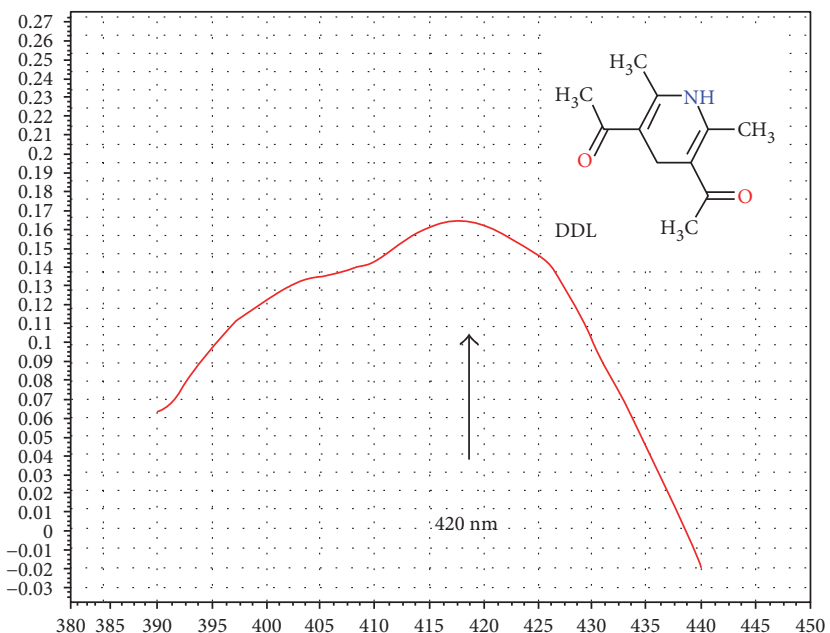

(c)

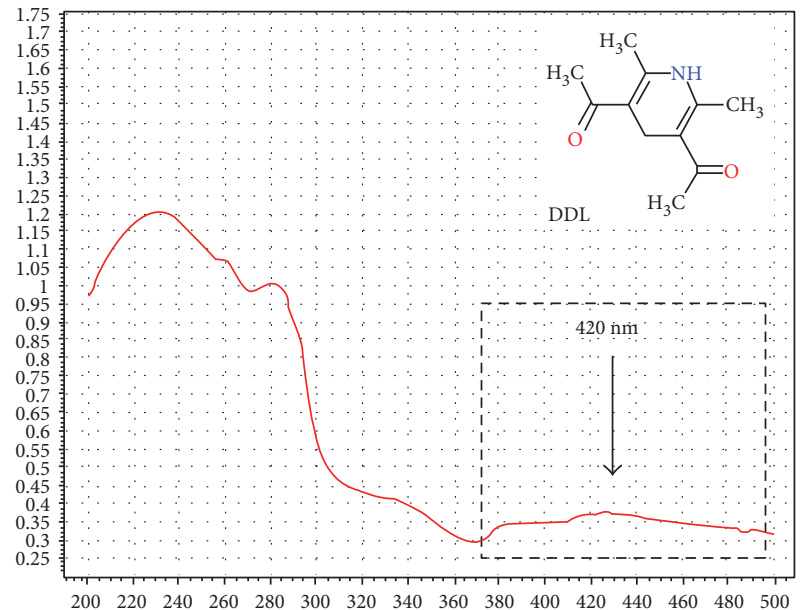

(b)

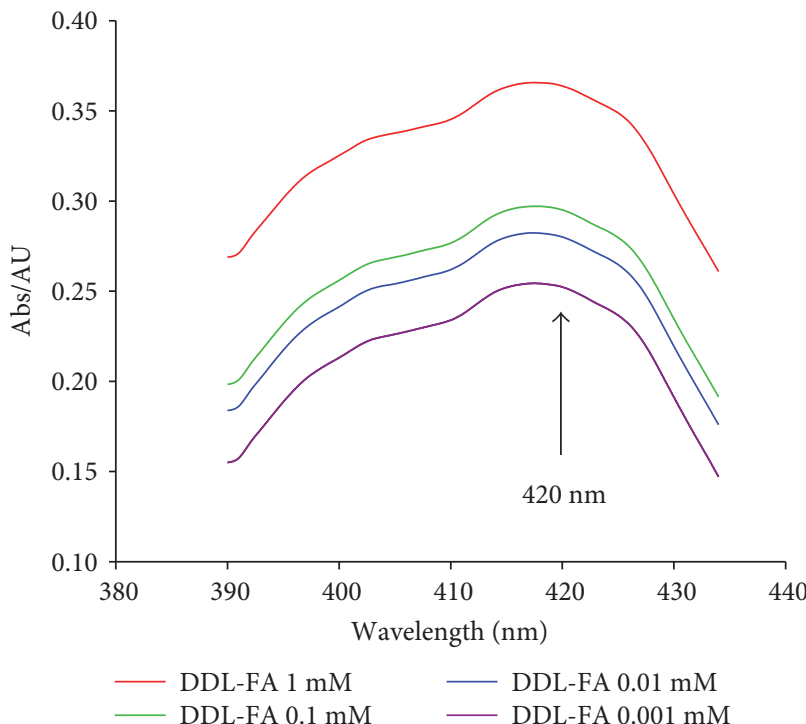

(d)

FIGURE 1: The spectrograph of Fluoral-P (a), DDL (b), and the amplified spectrum of DDL (c). The dose-dependent UV absorption peak of DDL at $420 \mathrm{~nm}$ derived from the reaction between Fluoral-P $(0.5 \mathrm{mM})$ and FA (d) $(0.001,0.01,0.1$, and $1 \mathrm{mM}$, resp.).

available online at https://doi.org/10.1155/2017/9043134). There were no significant differences between the groups with respect to demographic data.

2.9. Statistical Analysis. Graphs were generated using GraphPad Prism version 5.01 (GraphPad Software Inc., San Diego, CA, USA). Statistical analyses were generated using SPSS software version 21.0 (SPSS Inc., Chicago, IL, USA). In the Morris water maze experiment, Fisher's least significant difference was used for post hoc comparisons, and the difference between the different treatment groups within each consecutive day was analyzed by using a one-way ANOVA. For other experiments, statistical significance was determined by using a one-way ANOVA followed by Tukey's post hoc test. The data is represented as mean \pm standard error over three independent experiments. $P<0.05$ was considered statistically significant.

\section{Results}

3.1. The UV Absorption Peak of FA, Fluoral-P, and DDL. To confirm the proposed mechanism of the derivative reaction between two colorless reagents (FA and Fluoral-P produce a colored compound, DDL $[21,22]$ ), we first observed the changes in the color of the mixture between Fluoral-P and FA. Soon after the addition of Floural-P, a yellow DDL was generated (Supplementary Figure 2), and the UV absorption peaks were determined. Results showed that there was not an obvious absorption peak at $420 \mathrm{~nm}$ in the colorless Fluoral-P solution (Figure 1(a)), but following an addition of FA solution, a marked peak at $420 \mathrm{~nm}$ was sensitively detected at several seconds (Figures 1(b) and 1(c)). Notably, there was a dose-dependent absorbed peak of DDL $(420 \mathrm{~nm})$ formation between Fluoral-P $(0.5 \mathrm{mM})$ and $\mathrm{FA}$ at different concentrations (Figure 1(d)). These data suggest that the 


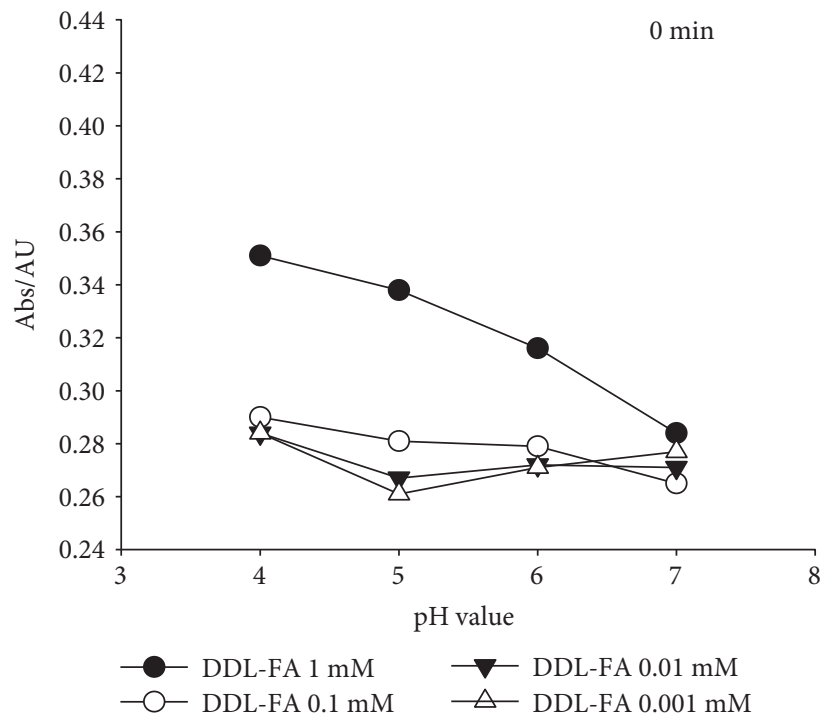

(a)

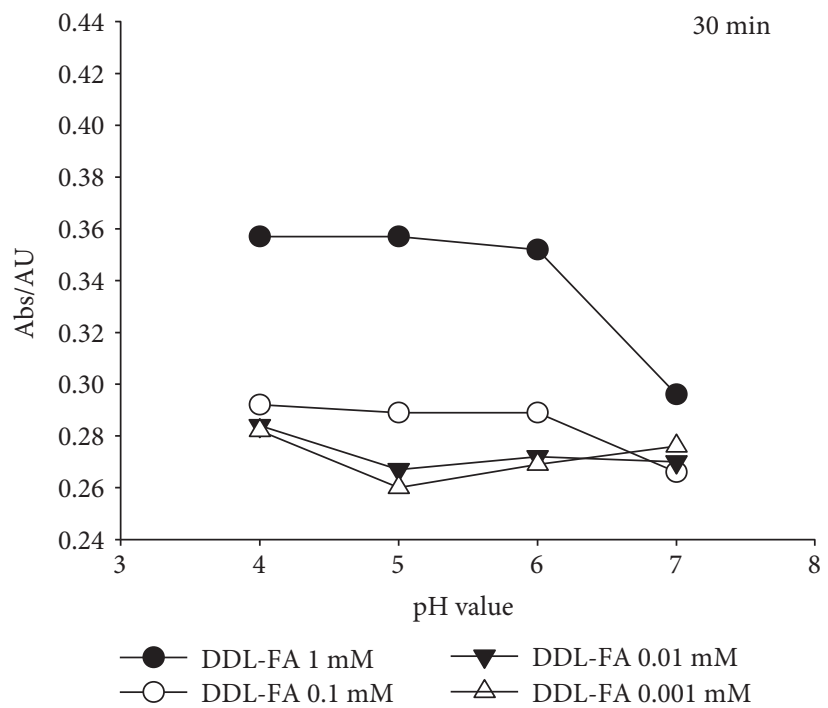

(c)

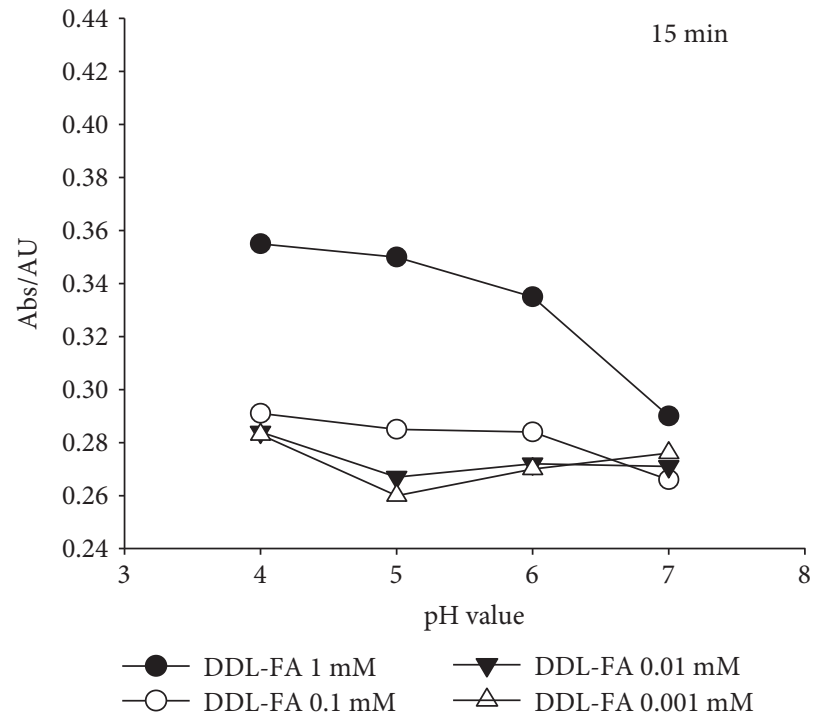

(b)

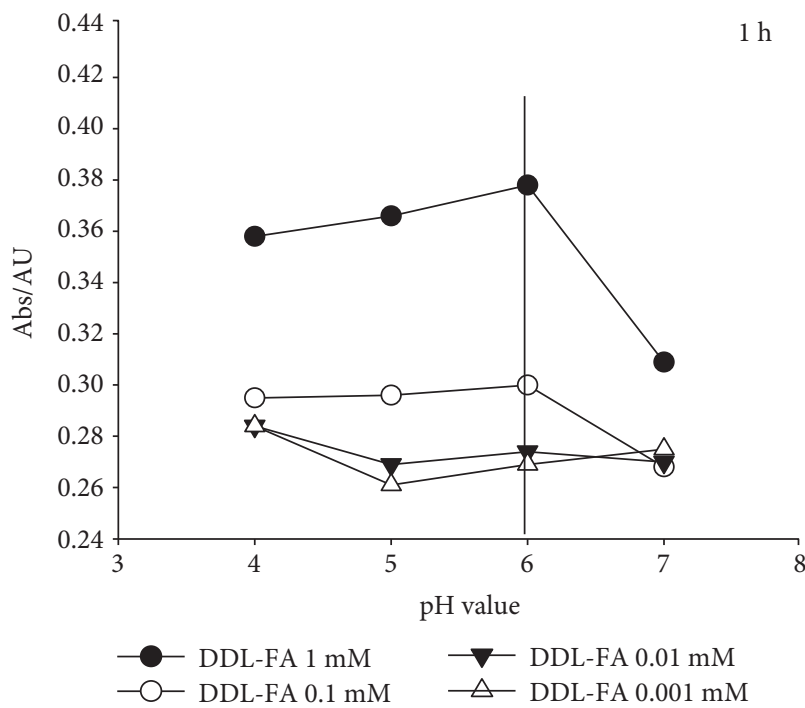

(d)

Figure 2: Changes in the UV absorption peak of DDL at $420 \mathrm{~nm}$ following the reaction between Fluoral-P $(0.5 \mathrm{mM})$ and FA (0.001, $0.01,0.1$, and $1 \mathrm{mM}$ ), after incubation at $0 \mathrm{~min}(\mathrm{a}), 15 \mathrm{~min}$ (b), $30 \mathrm{~min}$ (c), and $60 \mathrm{~min}$ (d), respectively.

FA derivative, DDL, is a candidate for spectrophotometric detection of FA.

3.2. Optimization of the Reaction Condition for FA Derivative-DDL. To obtain high sensitivity for this method, we explored a number of experimental parameters, such as reaction $\mathrm{pH}$, reaction time, and reaction temperature. First, the effects of $\mathrm{pH}$ on the formation of DDL at different times were investigated during the derivative reaction. The results showed that UV absorption values of DDL at 0,15 , and 30 min were gradually decreased with an increasing range of $\mathrm{pH}(\mathrm{pH} 4.0-7.0)$ of the Fluoral-P/FA mixture at room temperature $\left(25 \pm 1^{\circ} \mathrm{C}\right)$ (Figures $2(\mathrm{a}), 2(\mathrm{~b})$, and $\left.2(\mathrm{c})\right)$. Interestingly, the absorption values of DDL were increased to a maximum of 0.379 at $\mathrm{pH} 6.0$, but markedly decreased after the first hour (Figure 2(d)).
The standard curves of DDL derived from FA $(0.001$, $0.01,0.1$, and $1 \mathrm{mM}, \mathrm{pH} 6.0)$ and Fluoral-P (0.5 mM, pH 6.0) at $0,15,30$, and 60 minutes, respectively, were determined to be linear $(R>0.999)$, but there was a significant difference among the slopes of four regression equations (Figures 3(a) and 3(b)). These results suggest that the optimal conditions for the derivative reaction of DDL are $\mathrm{pH}$ : 6.0; reaction time: $1 \mathrm{~h}$; and reaction temperature: room temperature.

3.3. The Limit of FA Detection. Next, we determined the upper limit of FA detection from this method with results indicating that an absorbance of $420 \mathrm{~nm}$ was found when Fluoral-P (0.5 mM, pH 6.0) was added to solutions ( $\mathrm{pH} 6.0$ ) at or equal to $10 \mathrm{mM} F A$ for $1 \mathrm{~h}$. Any concentrations higher than $10 \mathrm{mM}$ (at optimal conditions) FA did not produce a linear change in UV absorbance of $420 \mathrm{~nm}$ over the first hour 

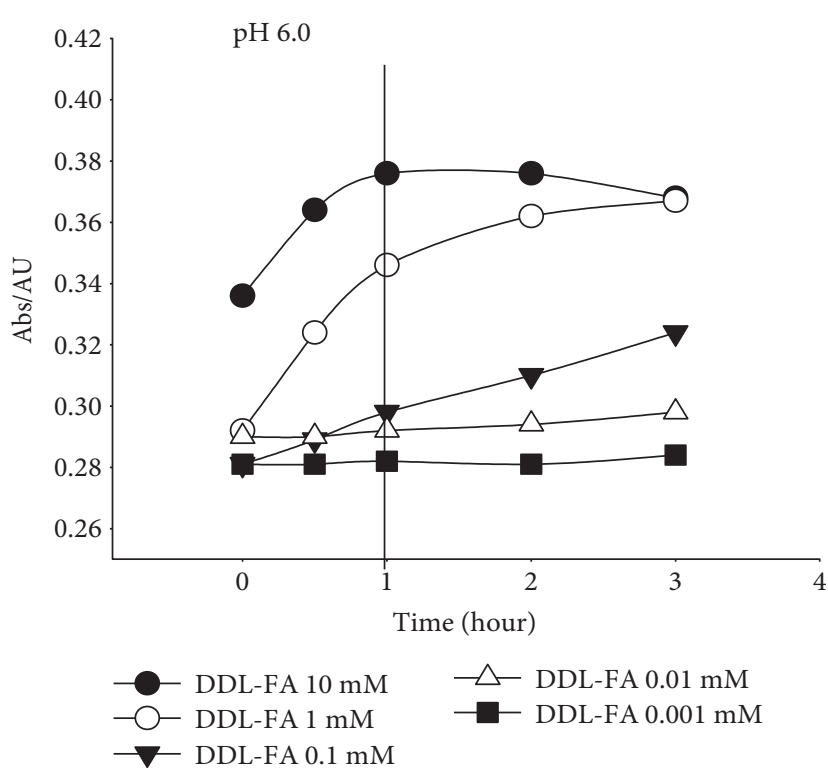

(a)

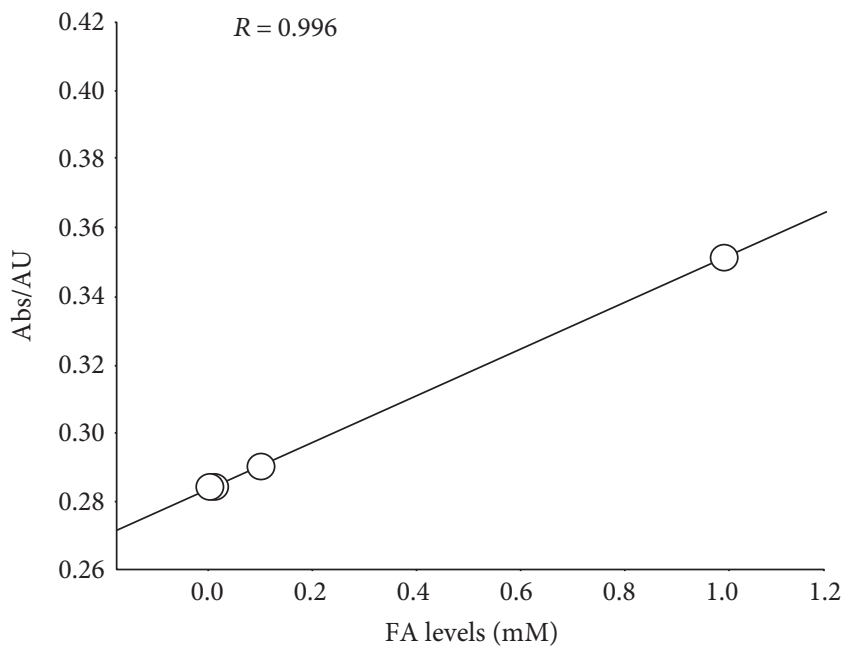

(c)

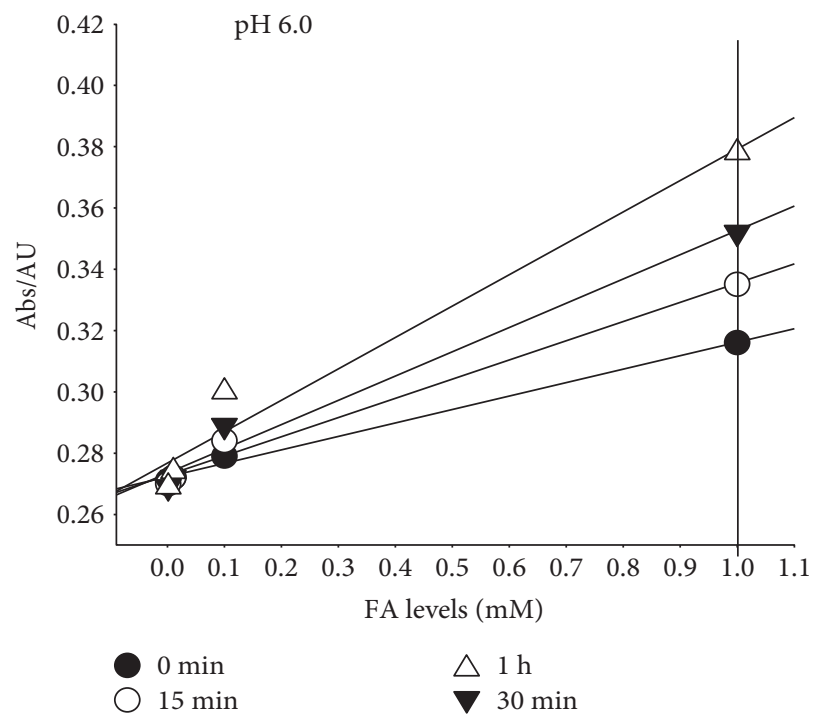

(b)

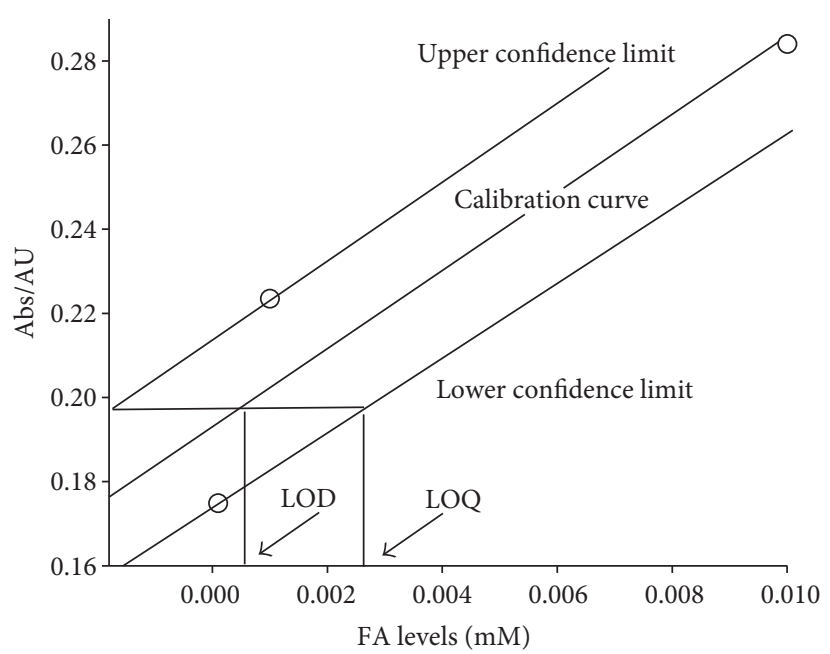

(d)

Figure 3: Determination of the response times at the optimized pH 6.0 (a), the different standard curves of DDL at different times (b), the standard curve at $1 \mathrm{~h}$ (c), and the LOD and LOQ of this spectrophotometric method at $1 \mathrm{~h}(\mathrm{~d})$.

(Figures 3(a) and 3(b)), thus suggesting that the upper limit of FA detection for using this method is $10 \mathrm{mM}$.

The actual concentrations of FA at $\mathrm{pH} 6.0$ within the standard curve at $1 \mathrm{~h}$ were $0.001,0.01,0.1$, and $1 \mathrm{mM}$, respectively. The regression equation of the calibration curve was $y=0.067$ and $x+0.283$ with a linear regression coefficient $(R)$ of 0.999 (Figure 3(c)). In the routine analysis, a one-point calibration in duplicate could be used instead of a calibration curve, but a new calibration curve was prepared to check the instrumental system in case of any deviation. The limit of detection (LOD) and the limit of quantization (LOQ) were calculated from the confidence intervals of the regression line of the calibration line following the method as previously described [23-25]. The LOD and LOQ of the method were 0.5 and $2.5 \mu \mathrm{M}$, respectively (Figure 3(d)).
3.4. The Repeatability and Stability of the Method. Nine replicates of control brain samples were analyzed at various time points in a day to evaluate within-day variations. The same samples of above brain homogenates were also analyzed on different days to evaluate day-to-day variations. The data of variations of within-day are summarized in Table 1 . These data indicate that there was no difference in concentrations of FA in brain samples within a day (average levels: 0.2705 $\pm 0.0045 \mathrm{mM} ; P>0.05$ ). The results of variation of day-today showed that the average relative standard deviations were less than $5 \%$ (Table 2). These data indicate that this method can accurately and precisely determine concentrations of FA in the brain samples.

3.5. Analysis of Brain FA and Assessment of FA Neurotoxicity. Finally, to investigate whether this method can assess the 
TABLE 1: Concentrations of mice brain formaldehyde within a day at different time points.

\begin{tabular}{|c|c|c|c|c|c|c|c|}
\hline Numbers & $0 \mathrm{~min}$ & $15 \mathrm{~min}$ & $30 \mathrm{~min}$ & $1 \mathrm{~h}$ & $1.5 \mathrm{~h}$ & $2 \mathrm{~h}$ & $3 \mathrm{~h}$ \\
\hline Sample 1 & 0.273 & 0.274 & 0.275 & 0.276 & 0.276 & 0.277 & 0.281 \\
\hline Sample 2 & 0.256 & 0.258 & 0.258 & 0.257 & 0.256 & 0.258 & 0.26 \\
\hline Sample 3 & 0.266 & 0.267 & 0.268 & 0.267 & 0.266 & 0.267 & 0.271 \\
\hline Sample 4 & 0.268 & 0.269 & 0.269 & 0.269 & 0.268 & 0.269 & 0.271 \\
\hline Sample 5 & 0.27 & 0.272 & 0.272 & 0.272 & 0.272 & 0.272 & 0.274 \\
\hline Sample 6 & 0.261 & 0.261 & 0.261 & 0.262 & 0.262 & 0.262 & 0.265 \\
\hline Sample 7 & 0.252 & 0.251 & 0.251 & 0.253 & 0.253 & 0.252 & 0.255 \\
\hline Sample 8 & 0.261 & 0.261 & 0.26 & 0.261 & 0.26 & 0.26 & 0.263 \\
\hline Sample 9 & 0.318 & 0.319 & 0.319 & 0.317 & 0.315 & 0.316 & 0.318 \\
\hline Mean \pm S.D. & $0.2694 \pm 0.0064$ & $0.2702 \pm 0.0065$ & $0.2703 \pm 0.0065$ & $0.2704 \pm 0.0063$ & $0.2698 \pm 0.0061$ & $0.2703 \pm 0.0063$ & $0.2731 \pm 0.0061$ \\
\hline
\end{tabular}

Data in means $(n=9)$. No significant difference among the values within a day $(P>0.05)$.

TABLE 2: Changes in formaldehyde (FA) concentrations in the brains of C57 mice at different days.

\begin{tabular}{lcccccc}
\hline Days & $1 \mathrm{~d}$ & $7 \mathrm{~d}$ & $14 \mathrm{~d}$ & Mean & S.D. & RSD $/ \%$ \\
\hline Brain FA $(\mathrm{mM})$ & 0.2746 & 0.2787 & 0.2704 & 0.2746 & 0.0041 & 1.511 \\
\hline
\end{tabular}

Data in means $(n=9)$. No significant difference among the values on different days $(P>0.05)$.

changes in FA levels in the different brains samples, we detected FA contents in the brains of FA-injected mice after intraperitoneal injection of FA $30 \mathrm{~min}(n=9)$ and these autopsy hippocampal tissues from $\mathrm{AD}$ patients $(n=9)$ and age-matched controls $(n=8)$. The results showed that there was a marked elevation in brain FA levels in the FAinjected mice compared with the control mice (con groups: $0.279 \pm 0.012 \mathrm{mM}$; FA groups: $0.395 \pm 0.017 \mathrm{mM} ; p<0.01)$ (Figure 4(a)). More importantly, these FA-injected mice associated with higher levels of FA exhibited more severe impairments in memory behaviors in Morris water mazes than the control mice (Supplementary Figure 1). Moreover, FA concentrations in autopsy samples from $\mathrm{AD}$ patients were significantly higher than those of age-matched controls (con groups: $0.286 \pm 0.021 \mathrm{mM}$; $\mathrm{AD}$ groups: $0.420 \pm 0.013 \mathrm{mM}$; $p<0.01$ ) (Figure 4(b)). These results indicate that our novel new spectrophotometric method is suitable to detect FA concentrations in the brain and suggesting that excess FA indeed induces cognitive impairments.

\section{Discussion}

Several decades ago, the colorless reagent, Fluoral-P, was confirmed to be a derivative reagent for the rapid detect FA in waste water, indoor air, and liquor [22, 26, 27], but to our knowledge, was never used to measure FA in brain tissues. In the present study, a highly selective spectrophotometric method using Fluoral-P, which selectively reacts with FA to produce a colored compound-DDL for the sensitive determination of FA in brain samples, was developed. Compared with GC/MS and HPLC methods, the sample preparation process and derivative of the reaction method were relatively simple and straightforward. Herein, this spectrophotometric method is a promising and potential practical application for detecting FA in the brains.

Substantial evidence has shown that gaseous FA can induce cognitive impairments in animals and humans $[5,8]$. During aging, chronic accumulation of endogenous FA is thought to be a risk factor for sporadic age-related dementia $[10,28]$. Furthermore, excess FA has been found to contribute to the pathological aggregation of amyloid fragments and tau hyperphosphorylation in normal adult mice and monkeys [29, 30]. More importantly, a direct intracerebroventricular injection of excess FA into animal models causes memory decline [13-15]. Thus, it is necessary to determine the concentrations of endogenous FA in biological tissues.

To date, various analytical methods have been developed to detect endogenous FA. For instance, using a FA detection kit, a two-fold increase in the levels of FA $(0.016 \mathrm{mM})$ was found in the cerebrospinal fluid of monkeys given an intracerebroventricular injection of methanol [31], which induced cognitive impairments, AD-like amyloid plaques, and tau hyperphosphorylation [30]. Using HPLC-Fluo, endogenous concentrations of FA in human blood and urine were found to be approximately 0.08 and $0.03 \mathrm{mM}$, respectively $[12,32]$. Likewise, using HPLC-UV to determine levels of 2,4-dinitrophenylhydrazine, a derivative agent, showed that FA concentrations in the urine of normal Sprague-Dawley rats and humans were approximately $0.01 \mathrm{mM}$ [33]. A method of headspace gas chromatography revealed that the concentrations of FA in human urine were between 0.019 and $0.048 \mathrm{mM}$ [34]. Moreover, the endogenous FA concentrations in brain samples of control mice detected in the current study were approximately $0.27 \mathrm{mM}$, which is consistent with the previous reports using HPLC-Fluo [20], HPLC-UV [19], and GC-MS [17].

\section{Conclusion}

Using this modified Fluoral-P method, an abnormally high level of FA was detected in brain samples of FA-injected mice (Supplementary Figure 3). Taken together, the present spectrophotometric method using Fluoral-P as a derivative reagent for measurement of FA in brain samples constitutes a simple, 


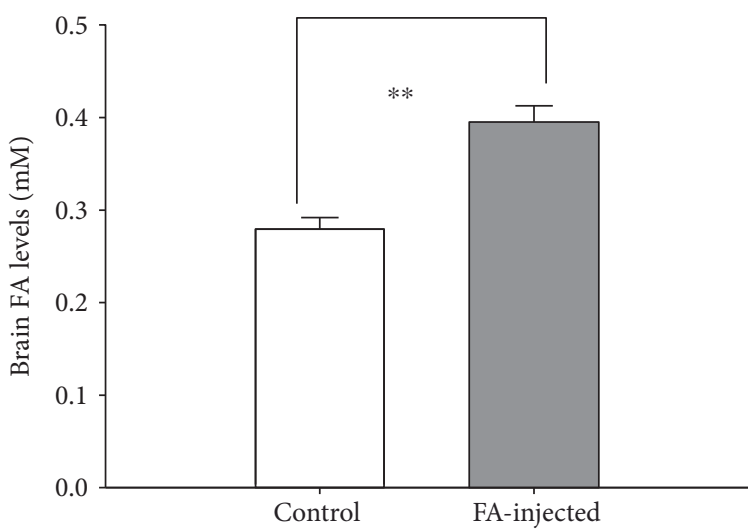

(a)

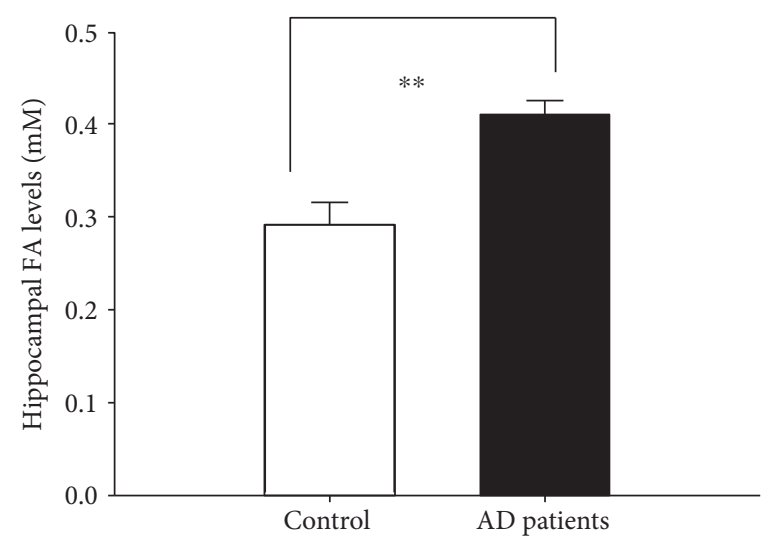

(b)

FIgURE 4: Changes in the brain FA concentrations of the FA-injected mice (a) and autopsy hippocampal tissues from AD patients (b).

sensitive, and practicable alternative to well-established methods for determining brain FA and assessing neurotoxicity of excess FA.

\section{Conflicts of Interest}

The authors declare no competing financial interests.

\section{Authors' Contributions}

Xiangpei Yue, Yaoyue Zhang, and Wen Xing contributed equally to this work.

\section{Acknowledgments}

This work was supported by grants from the 973-Project (2016YFC1306302), the Scientific Research Common Program of Beijing Municipal Commission of Education (KM201510025014), the major projects fund of Beijing Institute for Brain Disorders (ZD2015-08), and the Natural Scientific Foundation of CCMU (2015ZR31 and 2016JS09).

\section{References}

[1] T. Salthammer, S. Mentese, and R. Marutzky, "Formaldehyde in the indoor environment," Chemical Reviews, vol. 110, pp. 2536-2572, 2010.

[2] X. Tang, Y. Bai, A. Duong, M. T. Smith, L. Li, and L. Zhang, "Formaldehyde in China: production, consumption, exposure levels, and health effects," Environment International, vol. 35, pp. 1210-1224, 2009.

[3] M. Krzyzanowski, "WHO air quality guidelines for Europe," Journal of Toxicology and Environmental Health, Part A, vol. 71, pp. 47-50, 2008.

[4] K. H. Kilburn and R. H. Warshaw, "Neurobehavioral effects of formaldehyde and solvents on histology technicians: repeated testing across time," Environmental Research, vol. 58, pp. 134-146, 1992.

[5] K. H. Kilburn, R. H. Warshaw, and J. C. Thornton, "Formaldehyde impairs memory, equilibrium, and dexterity in histology technicians: effects which persist for days after exposure," Archives of Environmental Health, vol. 42, pp. 117-120, 1987.
[6] S. E. Usanmaz, E. S. Akarsu, and N. Vural, "Neurotoxic effects of acute and subacute formaldehyde exposures in mice," Environmental Toxicology and Pharmacology, vol. 11, pp. 93100, 2002.

[7] Y. Liu, Z. Ye, H. Luo et al., "Inhalative formaldehyde exposure enhances aggressive behavior and disturbs monoamines in frontal cortex synaptosome of male rats," Neuroscience Letters, vol. 464, pp. 113-116, 2009.

[8] Z. Lu, C. M. Li, Y. Qiao, Y. Yan, and X. Yang, "Effect of inhaled formaldehyde on learning and memory of mice," Indoor Air, vol. 18, pp. 77-83, 2008.

[9] N. A. Taranenko and N. V. Efimova, "Biomonitoring of formaldehyde in the urinary samples from the pediatric population in the Irkutsk Region," Gigiena I Sanitariia, pp. 73-75, 2007.

[10] Z. Tong, C. Han, W. Luo et al., "Accumulated hippocampal formaldehyde induces age-dependent memory decline," Age (Dordrecht, Netherlands), vol. 35, pp. 583-596, 2013.

[11] J. Yu, T. Su, T. Zhou et al., "Uric formaldehyde levels are negatively correlated with cognitive abilities in healthy older adults," Neuroscience Bulletin, vol. 30, pp. 172-184, 2014.

[12] Z. Q. Tong, J. Zhang, W. H. Luo et al., "Urine formaldehyde level is inversely correlated to mini mental state examination scores in senile dementia," Neurobiology of Aging, vol. 32, pp. 31-42, 2011.

[13] Y. Mei, C. Jiang, Y. Wan et al., "Aging-associated formaldehyde-induced norepinephrine deficiency contributes to age-related memory decline," Aging Cell, vol. 14, pp. 659$668,2015$.

[14] A. Songur, O. A. Ozen, and M. Sarsilmaz, "The toxic effects of formaldehyde on the nervous system," Reviews of Environmental Contamination and Toxicology, vol. 203, pp. 105$118,2010$.

[15] A. Gurel, O. Coskun, F. Armutcu, M. Kanter, and O. A. Ozen, "Vitamin E against oxidative damage caused by formaldehyde in frontal cortex and hippocampus: biochemical and histological studies," Journal of Chemical Neuroanatomy, vol. 29, pp. 173-178, 2005.

[16] Z. Tong, C. Han, M. Qiang et al., "Age-related formaldehyde interferes with DNA methyltransferase function, causing memory loss in Alzheimer's disease," Neurobiology of Aging, vol. 36, pp. 100-110, 2015.

[17] H. D. Heck, E. White, and M. Casanova-Schmitz, "Determination of formaldehyde in biological tissues by gas 
chromatography/mass spectrometry," Biomedical Mass Spectrometry, vol. 9, pp. 347-353, 1982.

[18] E. Sardi and E. Tyihak, "Simple determination of formaldehyde in dimedone adduct form in biological samples by high performance liquid chromatography," Biomedical Chromatography, vol. 8, pp. 313-314, 1994.

[19] B. Yilmaz, A. Asci, K. Kucukoglu, and M. Albayrak, "Simple high-performance liquid chromatography method for formaldehyde determination in human tissue through derivatization with 2, 4-dinitrophenylhydrazine," Journal of Separation Science, vol. 39, pp. 2963-2969, 2016.

[20] Z. Tong, C. Han, W. Luo et al., "Aging-associated excess formaldehyde leads to spatial memory deficits," Scientific Reports, vol. 3, p. 1807, 2013.

[21] Y. Suzuki, N. Nakano, and K. Suzuki, "Portable sick house syndrome gas monitoring system based on novel colorimetric reagents for the highly selective and sensitive detection of formaldehyde," Environmental Science \& Technology, vol. 37, pp. 5695-5700, 2003.

[22] T. Nash, "The colorimetric estimation of formaldehyde by means of the Hantzsch reaction," The Biochemical Journal, vol. 55, pp. 416-421, 1953.

[23] C. Meier and F. Zünd, "Statistical methods in analytical chemistry," Wiley-Interscience: New York, 424, 2000.

[24] A. Shrivastava and B. Gupta, "Methods for the determination of limit of detection and limit of quantitation of the analytical methods," Chronicles of Young Scientists, vol. 2, pp. 21-25, 2011.

[25] J. Uhrovcik, "Strategy for determination of LOD and LOQ values-some basic aspects," Talanta, vol. 119, pp. 178180, 2014.

[26] L. S. Teixeira, E. S. Leao, A. F. Dantas, H. L. Pinheiro, A. C. Costa, and J. B. de Andrade, "Determination of formaldehyde in Brazilian alcohol fuels by flow-injection solid phase spectrophotometry," Talanta, vol. 64, pp. 711-715, 2004.

[27] M. Khanmohammadi, N. Dalali, F. Karami, A. B. Garmarudi, and H. Nemati, "Quantitative determination of formaldehyde by spectrophotometry utilizing multivariate curve resolution," Bulletin of the Chemical Society of Ethiopia, vol. 26, pp. 299-304, 2012.

[28] J. D. Rizak, Y. Ma, and X. Hu, "Is formaldehyde the missing link in $\mathrm{AD}$ pathology? The differential aggregation of amyloidBeta with APOE isoforms in vitro," Current Alzheimer Research, vol. 11, pp. 461-468, 2014.

[29] M. Yang, J. Lu, J. Miao et al., “Alzheimer's disease and methanol toxicity (part 1): chronic methanol feeding led to memory impairments and tau hyperphosphorylation in mice," Journal of Alzheimer's Disease, vol. 41, pp. 1117-1129, 2014.

[30] M. Yang, J. Miao, J. Rizak et al., “Alzheimer's disease and methanol toxicity (part 2): lessons from four rhesus macaques (Macaca Mulatta) chronically fed methanol," Journal of Alzheimer's Disease, vol. 41, pp. 1131-1147, 2014.

[31] R. Zhai, N. Zheng, J. Rizak, and X. Hu, "Evidence for conversion of methanol to formaldehyde in nonhuman primate brain," Analytical Cellular Pathology (Amsterdam), vol. 2016, Article ID 4598454, 5 pages, 2016.

[32] W. Luo, H. Li, Y. Zhang, and C. Y. Ang, "Determination of formaldehyde in blood plasma by high-performance liquid chromatography with fluorescence detection," Journal of Chromatography. B, Biomedical Sciences and Applications, vol. 753, pp. 253-257, 2001.
[33] Y. Deng and P. H. Yu, "Simultaneous determination of formaldehyde and methylglyoxal in urine: involvement of semicarbazide-sensitive amine oxidase-mediated deamination in diabetic complications," Journal of Chromatographic Science, vol. 37, pp. 317-322, 1999.

[34] A. Takeuchi, T. Takigawa, M. Abe et al., "Determination of formaldehyde in urine by headspace gas chromatography," Bulletin of Environmental Contamination and Toxicology, vol. 79, pp. 1-4, 2007. 


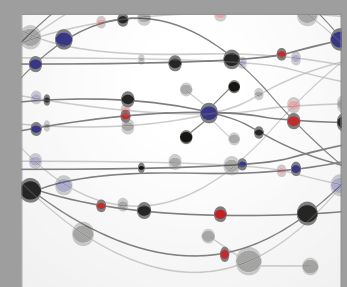

The Scientific World Journal
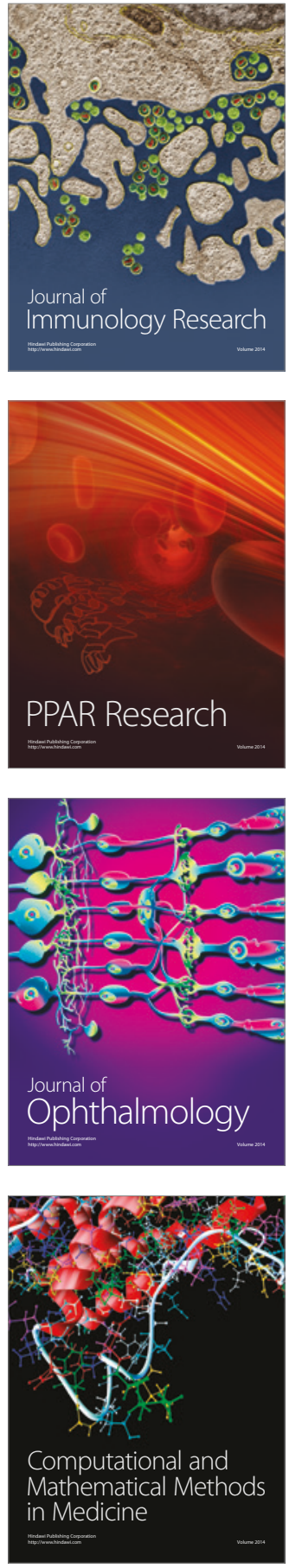

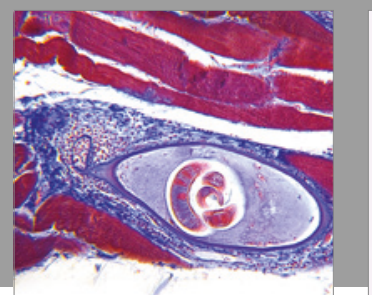

Gastroenterology Research and Practice
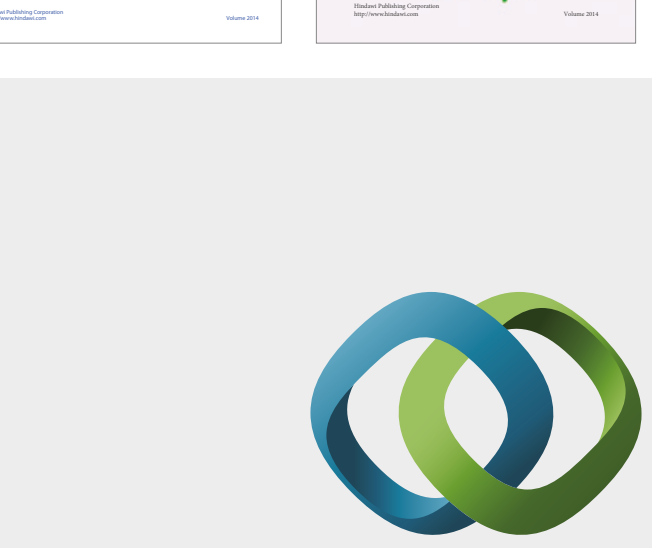

\section{Hindawi}

Submit your manuscripts at

https://www.hindawi.com
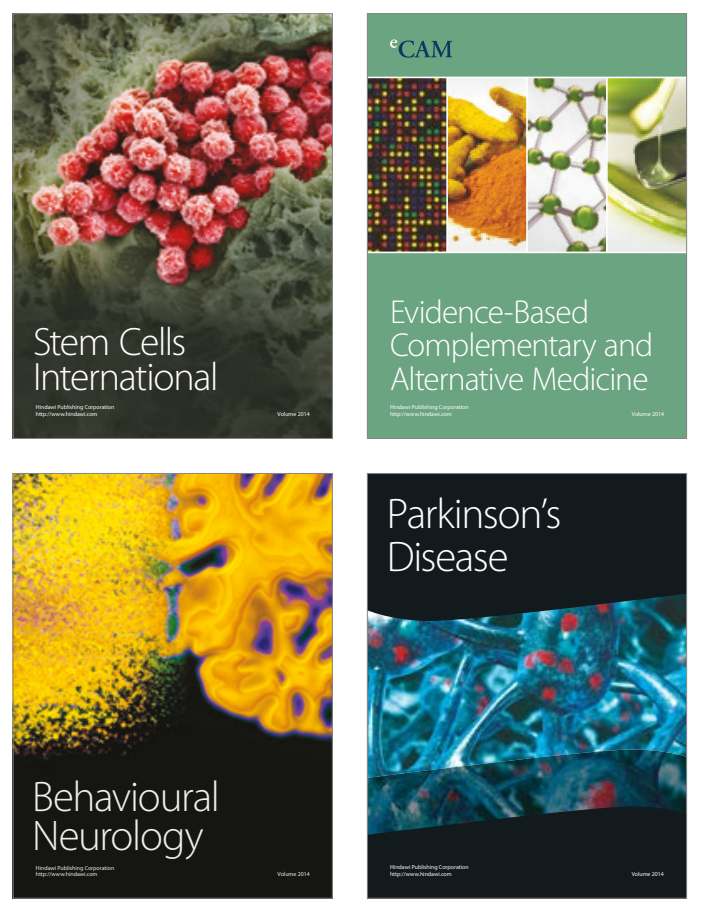
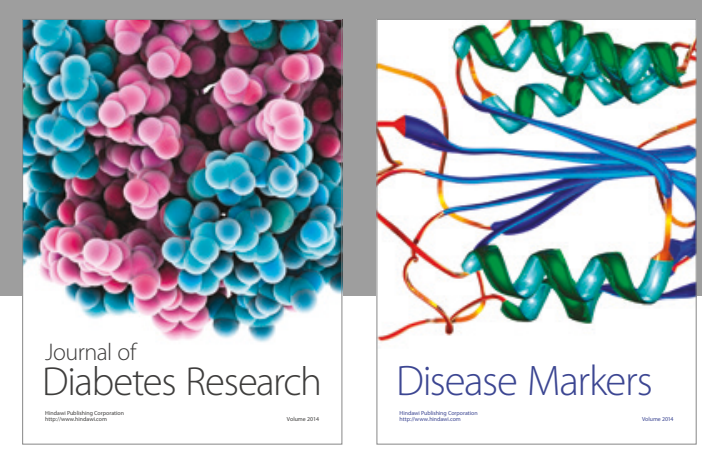

Disease Markers
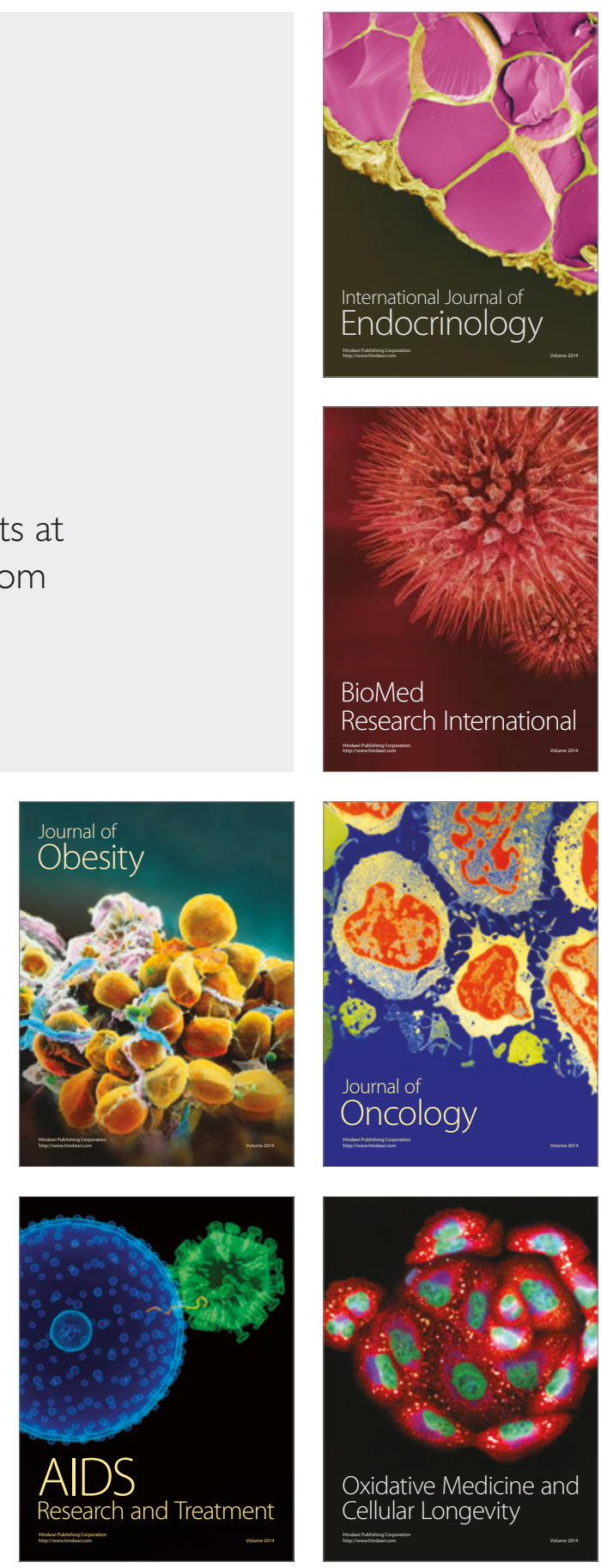